\title{
0 princípio constitucional da proporcionalidade e 0 seu lugar na metódica constitucional \\ - breves apontamentos a propósito da metáfora da balança
}

Mariana Canotilho ${ }^{1}$

SUMÁRIO: 1. A proporcionalidade como princípio metódico e pilar essencial de uma "Constituição mínima". 2. Proporcionalidade e direitos fundamentais. 3. Dificuldades práticas; 3.1. Os elementos de ponderação; 3.2. A linguagem métrica da proporcionalidade.

\section{A proporcionalidade como princípio metódico e pilar essencial de uma "Constituição mínima".}

O tema da proporcionalidade tem ocupado uma porção significativa do debate académico em matérias jurídico-públicas e, mais especificamente, jurídico-constitucionais, nas últimas décadas. Princípio aberto e maleável, tem-se revelado operativo no quadro de uma metódica constitucional da complexidade, uma vez que permite um conjunto de exercícios racionalizadores relevantes, no quadro

1 Docente da Faculdade de Direito da Universidade de Coimbra; Juíza Conselheira do Tribunal Constitucional, desde 2019. O texto serviu de base à intervenção no XIII Encontro de Professores de Direito Público, realizado na Faculdade de Direito da Universidade de Coimbra, a 24 de janeiro de 2020. 
da ponderação jurídico-constitucional, bem como uma vantagem operativa não ignorável, a saber:

i) a mobilização e consideração de um conjunto de direitos e valores constitucionalmente relevantes, em conflito ou dissonância entre si;

ii) a possibilidade de sopesar esses elementos, atendendo à sua distinta relevância, quer do ponto de vista da axiologia e arquitetura constitucionais, quer no que respeita às especificidades do caso concreto;

iii) a facilidade da construção de consensos, evitando discussões sobre a densificação de normas constitucionais de direitos fundamentais, que forçariam uma definição mais marcada do feixe de direitos, pretensões e faculdades que cada norma consagradora de um direito subjetivo fundamental confere aos cidadãos, seus titulares.

Estas significativas vantagens de ordem prática, levaram a que o princípio da proporcionalidade ganhasse progressiva relevância, sendo, hoje, um dos parâmetros de constitucionalidade mais frequentemente mobilizados como fundamento de um juízo de desconformidade com a Constituição, como amplamente demonstra a jurisprudência constitucional portuguesa.

A proporcionalidade (entendida em sentido amplo) é, pois, considerada como princípio geral de limitação da atividade do poder público - quer no que respeita à concretização de princípios jurídicos (como a subsidiariedade), quer quanto a medidas restritivas de direitos fundamentais - assumindo uma relevância crescente no plano da jurisprudência constitucional comparada, incluindo na jurisprudência dos tribunais supranacionais, como o Tribunal de Justiça da União Europeia (TJUE) ou o Tribunal Europeu dos Direitos Humanos (TEDH). O princípio expandiu-se de maneira significativa, e a discussão em torno do seu significado, operacionalidade, 
metodologia e limites constitui, hoje, um interessante diálogo global entre academias e jurisdições².

Não deixa de ser paradoxal que o frequentíssimo recurso ao princípio da proporcionalidade como fundamento de juízos de inconstitucionalidade, quer combinado com outros princípios fundantes do Estado de direito, - como o princípio da igualdade, ou, em Portugal, o princípio da proteção da confiança -, quer associado à avaliação de uma medida afetadora de direitos fundamentais, apareça, pelo menos de forma aparente, desligado de uma profunda reflexão, e até de uma opção jurisprudencial, em torno da correspondente teoria de direitos fundamentais. Ora, a opção pela proporcionalidade representa, amiúde, uma não opção pelos direitos. Ou seja, cada vez que se opta por mobilizar este fundamento, isoladamente, ou em conjugação com outros princípios fundamentais, faz-se uma opção

2 Cfr., entre outros: C. Bernal Pulido, El principio de proporcionalidade y los derechos fundamentales, Centro de Estudios Políticos y Constitucionales, Madrid, 2005; J. Christoffersen, Fair Balance: Proportionality, Subsidiarity and Primarity in the European Convention on Human Rights, Martinus Nijhoff Publishers, 2009; A. Barak, Proportionality - Constitutional rights and their limitations, Cambridge University Press, 2010; M. KLATT (ed.), Institutionalized Reason: The Jurisprudence of Robert Alexy, OUP, 2012; L. LAzArus, C. MACCRUdDEN (ed.), Reasoning Rights: Comparative Judicial Engagement, Hart Publishing, 2014; N. Petersen, Verhältnismäßigkeit als Rationalitätskontrolle: Eine rechtsempirische Studie verfassungsgerichtlicher Rechtsprechung zu den Freiheitsgrundrechten, Mohr Siebeck, 2015; V. Jackson / M. Tushnet (ed.), Proportionality: New Frontiers, New Challenges, Cambridge University Press, 2017; F. URBINA, A Critique of Proportionality and Balancing, Cambridge University Press, 2017; A. Stone Sweet e J. MATHEws, Proportionality Balancing and Constitutional Governance: A Comparative and Global Approach, OUP, 2019; D. GOnZÁlez CARVAllo / R. SÁnCHEZ Gil (coord.), El Test de Proporcionalidad, Convergencias y divergências, Centro de Estudios Constitucionales de la Suprema Corte de Justicia de la Nación, 2021.

Entre nós, por exemplo, J. ReIS NovaIs, Direitos Fundamentais: Trunfos contra a Maioria, Coimbra Editora, 2006; P. MACHETE / T. Violante, O Princípio da Proporcionalidade e da Razoabilidade na Jurisprudência Constitucional, também em relação com a Jurisprudência dos Tribunais Europeus, Relatório à XV Conferência Trilateral dos Tribunais Constitucionais de Espanha, Itália e Portugal, tribunal Constitucional, 2013; L. Nunes Vicente, O Princípio da Proporcionalidade - Uma nova abordagem em Tempos de Pluralismo, Faculdade de Direito da Universidade de Coimbra - Instituto Jurídico, 2014;V. CANAS, O Princípio da Proibição do Excesso na Conformação e no Controlo de Atos Legislativos, Almedina, 2017. 
jurídico-constitucional que escolhe a linguagem principialista da razoabilidade e da ponderação, em detrimento da linguagem, mais impositiva, dos direitos fundamentais. Por outro lado, mesmo quando a proporcionalidade é considerada enquanto parâmetro de validade de uma restrição a um direito fundamental - e, por isso, umbilicalmente associada a esse mesmo direito enquanto fundamento de um juízo de desconformidade com a Constituição - a verdade é que assim se sufraga uma determinada conceção de direitos fundamentais (em regra, de entre possíveis variações em torno da conceção alexiana de direitos prima facie) que, sendo talvez maioritária, hoje, pelo menos no quadro da jurisprudência e doutrina europeias, não é única, e é objeto de críticas que vale a pena considerar.

Mais ainda: é também paradoxal que o diálogo jurisprudencial e académico em torno da proporcionalidade pareça tão distante da discussão sobre a teoria da Constituição. O que foi e o que é, hoje, uma Constituição, para que serve, em que termos devem ser consideradas e jurisdicionalmente impostas, por um lado, as fronteiras nela traçadas à atuação dos poderes públicos e, por outro lado, as imposições de atuação a esses mesmos poderes?

A supremacia paramétrica - ainda que não em termos hierárquicos, mas simplesmente práticos - do princípio da proporcionalidade serve bem uma teoria da constituição mínima, reduzida a instrumento de governo (ou documento definidor do que R. Gargarella chamou a sala de máquinas da constituição ${ }^{3}$, referindo-se ao desenho dos órgãos de soberania e respetivas competências e relações de interdependência, ou seja, à forma de organização do poder político), conjugado com a garantia de respeito por um conjunto relativamente reduzido de princípios estruturantes (como a igualdade, a separação de poderes, ou a proporcionalidade) e por um catálogo de direitos fundamentais de densificação aberta. Na expressiva descrição de G. Almeida Ribeiro ${ }^{4}$, "a principal missão do poder constituinte, resignado à precariedade da sua força e legitimidade, é a de instituir as condições

3 Crf. R. Gargarella, La Sala, 2014.

4 G. Almeida Ribeiro, O conceito pós-moderno de constituição, in Atas do XII Encontro de Professores de Direito Público - O Poder Judicial: Revisitar o passado e pensar o futuro, Escola de Direito da Universidade do Minho, 2020. 
orgânicas e procedimentais de auto-determinação coletiva. (...) Em suma, só uma constituição mínima pode traduzir, na língua própria da pós-modernidade, o projecto de vida comum do constitucionalismo". Nestes termos, a proporcionalidade surge como mecanismo racionalizador de uma ponderação operada pelos titulares do poder - maxime, pelos juízes constitucionais - entre princípios, valores e direitos de natureza constitucional, sempre, a priori, de idêntico valor e necessariamente abertos a juízos de equilíbrio e concordância prática.

A questão torna-se, porém, mais inquietante, para quem não partilhe deste constitucionalismo mínimo, e se reveja numa - de entre várias - teoria da Constituição que a conceba como mais do que isso. Do constitucionalismo dirigente ao constitucionalismo crítico, passando pelo constitucionalismo transformador ou pela häberliana conceção do direito constitucional como ciência da cultura, até ao nascente constitucionalismo do comum, são múltiplos os entendimentos da Constituição como algo mais do que - ou, pelo menos, algo distinto de - um instrumento operativo do exercício do poder político democrático. Para os que subscrevam a premissa segundo a qual uma Constituição é mais do que o conjunto das suas disposições normativas, e constitui a opção por e a consagração de um projeto político concreto, democraticamente negociado e aprovado, expressão do específico contexto cultural e histórico de um povo, com um elemento de utopia e uma clara dimensão programática, impositiva, dirigente ou qualquer outra expressão que possa preferir-se -, em determinadas matérias, a redução de boa parte das questões de constitucionalidade a um debate em torno da sua proporcionalidade é problemática. É-o porque reduz, naturalmente, a possibilidade de afirmação de opções prefiguradas pelo legislador constituinte, imunes à ponderação tanto do legislador ordinário, quanto do juiz constitucional. Por outras palavras, para quem entenda que as constituições contêm específicos cadernos de encargos para o poder político constituído, há opções legislativas cuja inconstitucionalidade deve ser reconhecida antes mesmo de se recorrer ao princípio da proporcionalidade. Isto acontecerá sempre que se prefigure que o legislador constituinte consagrou uma regra constitucional expressa, que cristaliza uma opção, a priori, de concordância prática entre potenciais valores ou direitos em conflito, 
numa determinada situação, (por exemplo, proibindo certas restrições a um direito fundamental, ou limitando-as a casos pré-definidos no texto constitucional); resumindo, quando, por via interpretativa, se entenda estarmos perante "situações em que a própria Constituição garante uma faculdade, uma garantia, uma pretensão ou uma faceta particular do direito, mas já a título definitivo, absoluto, ou seja, o legislador constituinte fez logo ali, ele mesmo, todas as ponderações que havia a fazer e decidiu-se intencionalmente pela garantia, a título definitivo, do interesse jusfundamental em questão" ". Por outro lado, se se partilhar uma visão da Constituição axiologicamente comprometida, além do reduzido núcleo de princípios estruturantes acima mencionado, torna-se indispensável discutir o quê, e em que termos, pode (ou tem que) ser ponderado, em sede de mobilização do princípio da proporcionalidade.

Neste quadro, três questões fundamentais emergem, a meu ver, como incontornável objeto de reflexão: i) a problemática da conjugação entre a ideia de proporcionalidade e os direitos fundamentais enquanto critérios operativos de decisão judicial; ii) a necessidade de definição prévia e de delimitação dos elementos admissíveis de ponderação; iii) a questão das indefinições resultantes da linguagem métrica da proporcionalidade. A elas aludiremos, brevemente, nos pontos seguintes.

\section{Proporcionalidade e direitos fundamentais}

Todos os intérpretes de normas de direitos fundamentais compreendem que, para cada direito fundamental, existe um, ou vários, interesse(s) público(s) conflituante(s). Por outras palavras, e como ensina J. Weiler ${ }^{6}$, para além do que poderíamos designar como esfera ou núcleo fundamental (que não se confunde com o núcleo essencial), a definição e densificação do significado dos direitos fundamentais

5 Cfr. J. Reis Novais, Direitos Fundamentais, 2006, pp. 51.

6 Veja-se J. H. H. WeILER, Fundamental Rights and Fundamental Boundaries: Common Standards and Conflicting Values in the Protection of Human Rights in the European Legal Space, in R. KASTORYANO (ed.), An Identity for Europe, The Relevance of Multiculturalism in EU Construction, Palgrave Macmillan, 2011. 
constitui uma opção central de cada comunidade política, que reflete escolhas fundantes dessa mesma comunidade, moldadas pela sua identidade coletiva. Os concretos catálogos de direitos fundamentais e o seu significado são, pois, parte de uma identidade social partilhada, têm inegável relevância comunitária e podem originar conflitos quando mobilizados em espaços constitucionais distintos, como sucede quando normas ou decisões nacionais são apreciadas em tribunais supranacionais, como é o caso do TEDH. Exemplificando, é devido a isto que a fronteira de concordância prática entre os direitos fundamentais à liberdade de expressão (artigo 37. da CRP), por um lado, e ao livre desenvolvimento da personalidade e ao bom nome e reputação (artigo $26 .^{\circ}$ da CRP), por outro, é entendida de modo tão distinto no nosso país e fora dele que originou dezenas de condenações do Estado português pelo TEDH. Ou seja, sabemos que a interpretação das normas de direitos fundamentais implica a definição de limites, ou fronteiras fundamentais, correspondentes a valores com eles conflituantes. Se é sempre assim, dir-se-á, então é lógico que se mobilize em (quase) todos os casos o princípio da proporcionalidade, desdobrando-se a análise de conformidade constitucional nos passos necessários à verificação dos subprincípios dogmaticamente estatuídos de necessidade, adequação e proporcionalidade em sentido estrito.

Contudo, cabe questionar se isto será verdade em qualquer situação, ou em todas as circunstâncias. É relevante para a resposta a essa pergunta, antes de mais, a conceção de cada um sobre o que significa ter um direito fundamental; isto é, como acima se referiu, é incontornável mobilizar para esta reflexão a teoria dos direitos fundamentais. Aquela mesma pergunta é colocada, por exemplo, por M. Kumm na sua análise sobre a relação entre direitos fundamentais e proporcionalidade nas teses de Alexy, e as dificuldades que se levantam a esse respeito em sede de fiscalização da constitucionalidade.

7 Ver, por exemplo, M. Kumm, Alexy's Theory of Constitutional Rights and the Problem of Judicial Review, in M. KLATT (ed.), Institutionalized Reason: The Jurisprudence of Robert Alexy, OUP, 2012. 
É certo que R. Alexy constrói, na sua mais conhecida obra ${ }^{8}$, uma teoria dos direitos fundamentais que os concebe, do ponto de vista estrutural, de forma tão ampla e dúctil que permite (re)conciliá-los com as hodiernas práticas jurisdicionais em matéria de direitos humanos e direitos fundamentais, seguidas em boa parte das democracias constitucionais (e, em particular, das democracias do espaço europeu), bem como nos tribunais supranacionais com competência em matéria de direitos fundamentais. Fá-lo, simplificando, ao atribuir aos direitos a natureza estrutural de princípios, - entendidos como verdadeiros requisitos de otimização -, o que implica uma indispensável mobilização do princípio da proporcionalidade na sua adjudicação. Contudo, a verdade é que esta compreensão dos direitos difere da tradicional conceção liberal, nas suas distintas declinações ${ }^{9}$, acerca do que significa ter um direito. Quer se conceba como um trunfo contra a maioria, que o torna imune a ponderações ou afirma a sua prioridade sobre considerações acerca do bem, coletivamente determinado, ou, antes, como uma barreira de proteção contra exigências de interesse público, a realidade é que este entendimento dos direitos corresponde ao significado dos mesmos na linguagem comum e, em grande medida, às expectativas dos cidadãos. Neste sentido, é necessário definir o significado dos direitos fundamentais concretamente consagrados em cada catálogo; na verdade, se um direito subjetivo fundamental apenas conferisse ao seu titular um interesse constitucionalmente tutelado, obrigatoriamente mobilizável na ponderação de proporcionalidade a levar a cabo pelo intérprete constitucional, a realidade é que a diferença entre direitos fundamentais e quaisquer outros interesses atendíveis não se perspetivaria como significativa. E, no entanto, não se pode dizer que assim seja, pelo menos não em todos os casos, ou em relação a todo o âmbito de proteção garantido pelo direito.

Para aqueles que perfilhem uma qualquer teoria da Constituição que vá além da constituição mínima, impor-se-á, pois, a ideia

8 R. Alexy, A Theory of Constitutional Rights, OUP, 2010.

9 Vejam-se os clássicos de R. DwORKIN, Taking Rights Seriously, Harvard University Press, 1978 e J. Rawls, Political Liberalism, Columbia Classics in Philosophy, Columbia University Press, edição expandida, 2005. 
segundo a qual, pelo menos para alguns direitos, e/ou em relação a determinadas dimensões (faculdades parcelares) de um direito, o seu reconhecimento enquanto trunfos (ou outra figura análoga, reconduzível a uma ideia de indisponibilidade) é uma decorrência "do reconhecimento da força normativa da Constituição, da necessidade de levar a Constituição a sério: por maioritários que sejam, os poderes constituídos não podem pôr em causa aquilo que a Constituição reconhece como direito fundamental"10. Enquanto fronteiras à atuação dos poderes públicos, os direitos fundamentais excluem certas possibilidades da margem de conformação do legislador constituído, nos casos em que o legislador constituinte tenha entendido colocá-las para além de quaisquer considerações de razoabilidade ou proporcionalidade. Foi o que fez, por exemplo, o legislador constituinte português quando proibiu a pena de morte (artigo $18 .^{\circ},{ }^{\circ}{ }^{\circ} 2$, da CRP) e a tortura (artigo 19..$^{\circ}$, n. ${ }^{\circ} 2$, da CRP).

Nesta medida, é indispensável encontrar, na dogmática e na metódica constitucional, um equilíbrio entre a delimitação do conteúdo indisponível (ou do conjunto de faculdades parcelares indisponíveis) de certos direitos e a ponderação, com recurso ao princípio da proporcionalidade, nos restantes casos. No quadro português, e tendo em mente que a CRP proíbe "diminuir a extensão e o alcance do conteúdo essencial dos preceitos constitucionais" (artigo 18..$^{\circ}$ ), seria desejável refletir e procurar consensos crescentes em torno da amplitude desse conteúdo essencial, que deve ir além do tradicional núcleo essencial, se quisermos levar a sério a normatividade e essencialidade dos direitos fundamentais, enquanto fronteiras de um espaço de liberdade e autodeterminação, frente, antes de mais, ao Estado, mas também, e com relevância crescente, a outras entidades públicas e privadas.

Para tal, urge, desde logo, uma densificação das normas de direitos fundamentais pela sociedade aberta dos seus intérpretes, de preferência, prévia à sua aplicação pelos tribunais. Ou seja, os direitos precisam de conteúdo, sem o qual o espaço de decisão e determinação por parte do juiz se alarga, em termos potencialmente problemáticos, no que respeita à separação de poderes, numa sociedade democrática. No fundo, estamos apenas a dizer que, se os direitos fundamentais não podem ser sempre, em todos os casos, simples princípios, há que

10 J. ReIs NovaIS, Direitos Fundamentais, 2006, pp. 36. 
fazer um esforço dogmático no sentido de perceber onde e quando é que eles assumem uma estrutura mais próxima das regras. Por exemplo, quando o legislador constituinte estatuiu o direito ao recurso, em processo penal (artigo 32. ${ }^{\circ},{ }^{\circ}{ }^{1}$, da CRP), em que casos ou circunstâncias é que esse direito sempre se imporá ao legislador, e em quais pode ser objeto de ponderação em face de outros valores constitucionalmente protegidos? O campo de maior e melhor densificação a este nível - ainda que reste bastante trabalho por fazer - é, precisamente, o da chamada constituição penal, mas não há razões fundamentais para não se trilhar caminho semelhante noutras áreas.

\section{Dificuldades práticas}

Além da relação incontornável com a teoria da Constituição e a teoria dos direitos fundamentais de que acima se deu conta, a aplicação jurisprudencial do princípio da proporcionalidade coloca dificuldades práticas, mesmo no amplo espaço aberto à ponderação. Assinalaremos duas, em particular, sentidas com maior frequência.

\subsection{Os elementos de ponderação}

A primeira destas dificuldades centra-se na delimitação dos elementos de ponderação. Se se vai "pesar" direitos e valores constitucionalmente relevantes, o que pode estar nos pratos da balança? Estão os direitos prima facie, em toda a sua amplitude e generosidade definidora? A resposta comummente aceite a esta questão é hoje afirmativa, tendo sido abandonada, de forma progressiva, a teoria dos limites imanentes. Mas o equilíbrio deve ser procurado apenas quando estejam em causa valores com assento constitucional, ou também quando se trate de interesses formalmente infraconstitucionais, com relevância no caso concreto? Cremos que não deve o juiz constitucional ultrapassar a barreira da Lei Fundamental na delimitação do perímetro de relevância de tais elementos de ponderação ${ }^{11}$, sendo, porém, evidente que também o estabelecimento dessa barreira

11 É inversa a posição de J. ReIS NovaIS, Direitos Fundamentais, 2006, pp. 53, nota 43 . 
está sujeito a debate interpretativo e fundamentação. A verdade é que, pelo menos no caso português, a Constituição expressamente refere a necessidade de "salvaguardar outros direitos ou interesses constitucionalmente protegidos" (artigo 18. ${ }^{\circ}$, n. $^{\circ}$ 2). Nestes termos, deverá emitir-se um juízo de inconstitucionalidade sempre que se entenda que a norma questionada visa tutelar, restringindo um direito, ou com compressão assinalável de um princípio fundamental, um bem sem verdadeiro abrigo na Constituição. No fundo, levando a sério a sua força normativa e o seu específico projeto constitucional, admitir-se-á que há casos em que normas/medidas legislativas que parecem razoáveis, em face de uma avaliação global do caso concreto, não podem ser tidas como proporcionais, por não poderem levar-se em consideração os bens e interesses de natureza infraconstitucional que o legislador visava proteger.

Por outro lado, cabe notar a importância da justificação, fundamentação, e até da eventual prova de existência e/ou delimitação do direito, princípio ou valor constitucional que serve de elemento de ponderação. No fundo, a questão é esta: basta ao legislador ordinário invocar um qualquer direito ou valor com assento na CRP, para que o juiz deva considerar comprovada a sua existência, e os específicos contornos segundo os quais é descrito? Qual é o grau de escrutínio a que deve ser submetida a justificação apresentada pelo legislador, por exemplo, para uma medida restritiva de direitos fundamentais? Como se comprova a necessidade de tal medida, para que se possa considerar respeitado o primeiro subprincípio do juízo de proporcionalidade? Bastará a sua verosimilhança? Ou será exigível prova, pelo menos quando se funde em alegações quantitativa ou qualitativamente comprováveis? A verdade é que há, com alguma frequência, na fundamentação das medidas legislativas, afirmações de facto empiricamente verificáveis, como verdadeiras ou falsas. Seria, pois, fácil admitir que o juízo de inconstitucionalidade fundado na proporcionalidade não devesse evitar, no mínimo, essa comprovação; contudo, pode não ser trivial afirmá-la, até mesmo em face dos mecanismos processuais legislativamente definidos. Assim, na resposta a estas questões conflui uma análise e eventual reconstrução da arquitetura sistémica, no que tange à fiscalização da constitucionalidade, e aos problemas de separação e interdependência de poderes. 
Além das já referidas, outra das dificuldades da aplicação prática da proporcionalidade é de natureza metódica e consiste em definir se se adota um caminho metodológico de prioridade aos direitos (isto é, partindo do direito limitado de maneira alegadamente inconstitucional, e avaliando a medida conflituante à luz da dogmática da proporcionalidade aplicada às normas restritivas) ou, por outro lado, um caminho de otimização dos direitos ou bens constitucionalmente relevantes em oposição. As operações metodológicas a levar a cabo não conduzirão, pelo menos não necessariamente, a um resultado idêntico. Poderá também haver diferenças importantes consoante esteja em causa um interesse público ou outro direito subjetivo fundamental, diferenças essas assentes na própria natureza e estrutura dos direitos fundamentais. No fundo, questiona-se se haverá algum tipo de prioridade a conferir, na mobilização do princípio da proporcionalidade enquanto parâmetro de validade, ao direito cuja validade é invocada, e em que termos a mesma deveria operar. É uma questão discutidíssima entre a doutrina especializada na matéria ${ }^{12}$, e que nos conduz de volta à afirmação da necessidade de conjugar, em sede de interpretação constitucional, a metódica da proporcionalidade com uma teoria bem definida dos direitos fundamentais. Sucede que as respostas variarão em função da tese que se sufrague a esse respeito, e que será fundamental para encontrar soluções para casos difíceis, que se multiplicam em matérias como a liberdade de expressão e a liberdade religiosa (veja-se, por exemplo, a saga judicial sobre o uso do véu islâmico no local de trabalho, constituída, desde logo, pelas decisões do TJUE nos casos Achbita $^{13}$ e Bougnaoui ${ }^{14}$, e pela decisão do TEDH no caso Eweida and Others v. The United Kingdom ${ }^{15}$ ).

12 Ver, por exemplo, a discussão travada em vários dos artigos constantes de D. González Carvallo / R. Sánchez Gil (coord.), El Test, 2021.

13 V. Acórdão do TJUE, Samira Achbita c. G4S Secure Solutions, processo C-157/15, de 14 de março de 2017.

14 V. Acórdão do TJUE, Asma Bongnaoui c. Micropole SA, processo C-188/15, de 14 de março de 2017.

15 V. Acórdão do TEDH, Eweida and Others v. The United Kingdom, de 27 de maio de 2013. 


\subsection{A linguagem métrica da proporcionalidade}

Por último, cabe ainda lembrar que a metódica da proporcionalidade nos remete para juízos fundamentados com recurso a uma linguagem métrica, que não está isenta de crítica ou problematização.

Em primeiro lugar, há que considerar que, para muitos dos que sufragam uma teoria da Constituição além do mínimo, é relevante a constatação de que o específico projeto constitucional da CRP contém um importante catálogo de direitos económicos, sociais e culturais. Ora, nestes termos, há que lembrar que os direitos fundamentais podem - e devem - ser chamados aos juízos de ponderação, sem distinções de ordem hierárquica ou metodológica. Todos os direitos pesam, nas circunstâncias em que sejam mobilizáveis para a resolução de um caso concreto, pelo menos na sua dimensão negativa, de resistência à atuação do legislador, e esta premissa não deve ser afastada com fundamento na ausência de consenso sobre a densificação do sentido e alcance da dimensão positiva do direito. Ou seja, se levarmos a sério a metáfora da balança, não podemos deixar de considerar um direito de natureza social, como contrapeso aos direitos ou valores invocados pelo legislador para justificar uma norma cuja conformidade constitucional se vê questionada. Numa palavra, não é porque inexiste consenso sobre a dimensão prestacional de um direito como a habitação que o mesmo deve ser ignorado na avaliação da proporcionalidade de medidas que, por alguma razão, ainda que plenamente atendível, privam os titulares desse direito da habitação que já têm. Contudo, este tipo de direitos é frequentemente avaliado como tendo menos peso do que os seus contrapólos valorativos, ou até como sendo irrelevante para a ponderação, com fundamento na sua estrutura, natureza ou regime jurídico. Esta visão das coisas é problemática, pelo menos no quadro de certas teorias da Constituição e até mesmo de algumas teorias de direitos fundamentais, levantando questões metodológicas sobre proporcionalidade, respeitantes, essencialmente, à avaliação do cumprimento do subprincípio da necessidade.

Por outro lado, pode afirmar-se que a linguagem métrica é inerente às disposições de direitos fundamentais (que nos remetem para a ideia de standards, de maior e menor proteção, da menção a níveis 
elevados ou aos níveis mais elevados de tutela jusfundamental), pelo que não se afigura, a priori, desadequada para a fundamentação de juízos de ponderação e de conformidade constitucional. Contudo, é indispensável exigir a maior clareza possível quanto às operações metodológicas e aos fundamentos valorativos e axiológicos que presidem a tais juízos de ponderação. Não são desprovidas de sentido críticas como a de M. Tushnet ${ }^{16}$, quando, analisando casos célebres da jurisprudência alemã nos quais se recorre ao princípio da proporcionalidade, afirma que muitas das fundamentações aduzidas para justificar um juízo de inconstitucionalidade seriam facilmente reversíveis, do ponto de vista argumentativo, podendo sustentar um juízo de sentido inverso. A verdade é que a opção por uma ponderação fundada na proporcionalidade deve ser, ela própria, racionalizada em termos justificativos, em particular nos casos em que se escolhe o afastamento de uma linguagem dos direitos (em termos liberais), ainda logicamente invocável, preferindo-se o controlo de constitucionalidade menos denso permitido pela linguagem dos princípios. No entanto, é sabido que o problema não se coloca desta forma numa perspetiva puramente alexiana, o que nos remete, uma vez mais, para a perplexidade de uma aplicação do princípio da proporcionalidade, sem claras escolhas em sede de teoria dos direitos fundamentais.

Por fim, é inegável que a linguagem métrica se revela particularmente dificil em contextos de pluralismo (cultural, político) ou complexidade extrema, nos quais os chamados critérios de evidência (muitas vezes invocados pela jurisprudência constitucional) se revelam, amiúde, desadequados. Tendo em conta a atual realidade pós-pandémica, e os ensinamentos que dela podemos já retirar, esta dificuldade tenderá a crescer, quer no que respeita ao número de casos em que se levanta, quer quanto à magnitude com que se impõe ao julgador.

16 Cfr. M. Tushnet, Making Easy Cases Harder, in V. Jackson / M. Tushnet (ed.), Proportionality: New Frontiers, New Challenges, Cambridge University Press, 2017. 